\title{
Research on Seismic Response and Damping Effect for High-Speed Railway Seismic Isolated Bridge
}

\author{
Lingkun Chen $^{1,2}$, Lizhong Jiang ${ }^{1,2, *}$, Weiguo Long ${ }^{1,2,3}$ and Liping Wang ${ }^{1,2}$ \\ ${ }^{1}$ School of Civil Engineering, Central South University, Changsha 410075, China \\ ${ }^{2}$ National Engineering Laboratory for High Speed Railway Construction, Central South University, Changsha \\ 410075, China \\ ${ }^{3}$ School of Mathematics and Physics, University of South China, Hengyang 421001, Hunan, China
}

\begin{abstract}
With the development of high-speed railway in recent years, lots of researchers have been paying more and more attention to the seismic isolation of high-speed railway bridge. The equivalent linear model of hysteretic characteristics of lead rubber bearings (LRB) is presented, the computational method and the varying range of dynamic parameters effecting hysteretic characteristics of LRB are established. The finite model of a high-speed railway bridge including simulating of LRB is set up by ANSYS software. The seismic responses and seismic isolation ratio of high-speed isolated bridge installed LRB are calculated, and isolation effect are compared with those fabricated the common bearings; the factors which influence seismic isolation are analyzed. The calculation results show that the bending moment and shear force of pier bottom of and displacement of grider decrease effectively for that bridge with LRB, the LRB has excellent performance on seismic isolation and energy dissipation.
\end{abstract}

Keywords: Seismic response, damping effect, high-speed railway bridge, seismic isolation, LRB

\section{INTRODUCTION}

Bridges are lifeline structures; their failure during a seismic event will result in serious consequences and will hamper relief and rehabilitation work, the considerable attention has been paid to the research of the structural seismic isolation devices for reducing the affects of earthquake disaster in recent years, the workable technology of seismic isolation is used widely in America, Japan and so on, some valuable research results have been obtained [1-7]. The main principle of seismic isolation technology is: the seismic isolation bearings can decouple superstructure from substructure, prolong the natural period of vibration of structure, increase the damping of structure, and effectively decrease seismic responses of structure. In this paper the equivalent bilinear modal and design method of dynamic parameters of LRB are established, the finite model of a high-speed railway bridge is built up, the LRB is simulated perfectly by the ANSYS software, the dynamic responses of high-speed seismic isolated bridge are calculated, the isolation effect of isolated bridge is analyzed compared with bridge installed common bearings.

\section{HYSTERETIC ANALYSIS MODEL AND DYNAMIC PARAMETERS OF LRB}

\section{Equivalent Bilinear Model of LRB}

Initial stiffness of LRB is strengthened after inserting lead-core into the ordinary laminated rubber bearing, owing

*Address correspondence to this author at the School of Civil Engineering and Architecture, Central South University, Changsha 410075, China; Tel: +86 -731- 82655536; Fax: +86 -731- 82656611;

E-mail: lzhjiang@mail.csu.edu.cn to yield strength of lead plug is lower, the pre-yield stiffness of the LRB reduces greatly which will approach to the elastic stiffness of LRB under earthquake action, the plump hysteretic curve of LRB can be obtained, it show that LRB can dissipate seismic energy effectively. Many experiments results indicate that load-deformation relationship of LRB is nonlinear, Wen et al. [8-10] presented the differential hysteretic resorting force model by the research on dynamic hysteretic characteristics of structure, the model approach to practical situation to some extent and later hardening properties of LRB can be considered conveniently, the restoring force can be described by the following equations:

$F-\alpha K_{1} D+(1-\partial) Q_{d} z=0$

In which, $\mathrm{F}$ is the hysteretic restoring force; $\alpha$ is the ratio of post-yield and pre-yield stiffness; $K_{1}$ is the pre-yield stiffness; $D$ is the horizontal shear displacements of LRB; $Q_{d}$ is the yielding load; $z$ is the dimensionless form of hysteretic variation, $|z| \leq 1$, which can be calculated based on the following differential equation;

$\dot{z} D_{y}-A D+\gamma|\dot{D}| z|z|^{n-1}+\beta \dot{D}|z|^{n}=0$

$D_{y}$ is the yielding displacement; $A, \gamma, \beta$ are parameters which describe the hysteretic shape respectively, to LRB, $\mathrm{A}=1, \gamma=\beta=0.5 ; \mathrm{n}$ is feature parameter which control transition smoothness between the elastic stage and plastic stage, $\mathrm{n} \geq 1$, to LRB, $\mathrm{n}=2$.

The two-step solution algorithm is employed to solve the hysteretic model of LRB, that is, the unconditionally stable 
Newmark's constant-average-acceleration method is employed to solve the motion equation, and the unconditionally stable semi-implicit Runge-Kutta method is used to solve the differential equations governing the behavior of the nonlinear isolation elements.

As can be seen that Wen model is complicated to design of LRB, the hysteretic curve can be simplified into the bilinear curve by assuming effective stiffness and effective damping ratio for the sake of convenient in engineering application, the simplified method is made use of in ETABS, SAP and AASHTO [11], JPWRI [12], NZMWD [13], etc. The equivalent bilinear modal of LRB is shown in Fig. (1).

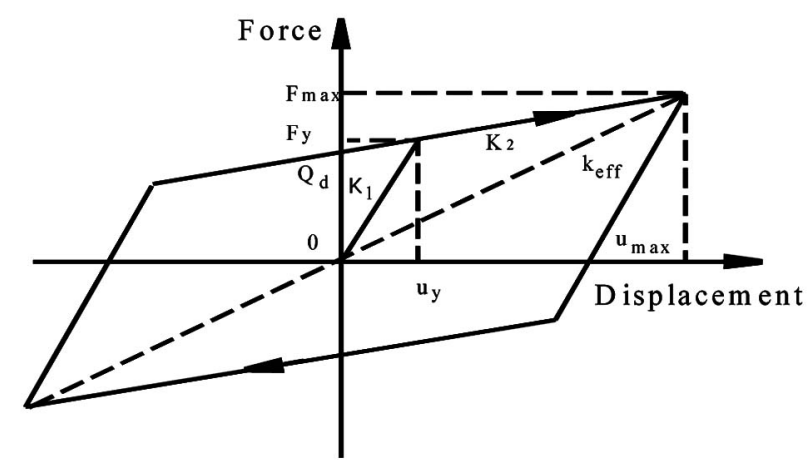

Fig. (1). Equivalent bilinear modal of LRB.

\section{DYNAMIC PARAMETERS OF LRB}

The computing formulas of the equivalent stiffness and damping of LRB which are presented in this-paper according to AASHTO [11].

$K_{\text {eff }}=\frac{1+\alpha(\mu-1)}{\mu} K_{1}$

$\xi_{e f f}-\xi_{0}=\frac{2(1-\alpha)(\mu-1)}{\pi \mu[1+\alpha(\mu-1)]}$

For the ideal bilinear model

$K_{\text {eff }}=K_{2}+\frac{Q_{d}}{d}$

$\xi_{\text {eff }}=\frac{2 Q_{d}\left(d-d_{y}\right)}{\pi K_{e f f} d^{2}}$

In which, $K_{\text {eff }}$ is the equivalent stiffness; $\xi_{\text {eff }}$ is the equivalent damping; $K_{1}$ is the pre-yield stiffness $K_{2}$ is the pre-yield stiffness ; $Q_{d}$ is the characteristic strength of LRB; $d$ is the design total deck displacement relative to ground; $d_{y}$ is yield displacement of LRB; $\alpha=\mathrm{K}_{2} / \mathrm{K}_{1}$ is the hardening ratio; $\xi_{0}$ is the damping ratio of structure.

The computational formulas of post-yielding stiffness and characteristic strength of LRB are presented in reference [11].

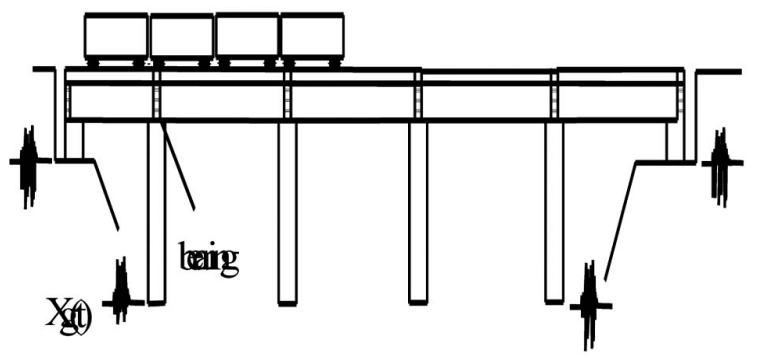

Fig. (2). Model of five-span simply supported bridge.

\section{EARTHQUAKE RESPONSES ANALYSIS CASE OF SEISMIC ISOLATED BRIDGE}

\section{Basic Parameters of Five-Span Simply Supported Bridge}

A five-span simply supported box bridge under highspeed trains is taken as the calculation model to analyze the damping effect of seismic isolated bridge in this paper, the related parameters are listed below: $32 \mathrm{~m}$ span concrete prestressed concrete box girder, $2.3 \mathrm{~m} \times 6.0 \mathrm{~m}$ round-shaped solid piers which are cast in situation and concrete strength grade is $\mathrm{C} 35$, the designed horizontal earthquake acceleration $\mathrm{a}=0.2 \mathrm{~g}$, the rare horizontal earthquake acceleration $\mathrm{a}=0.4 \mathrm{~g}$. The finite element model of five-span simply supported bridge is shown in Fig. (2).

\section{SIMULATING OF LRB}

The ANSYS software is employed to establish the space analysis model of the five-span simply supported box bridge under high-speed trains in this paper, the Beam 188 element is utilized to simulate box beam and pier, the bottom of piers is proposed consolidated not considering Soil-Pile Interaction. Nowadays the pot rubber bearings have been widely used in the high-speed railway bridge, the Combin 14 unit is employed to simulate horizontal and vertical stiffness of the pot rubber bearings; the mechanical model of isolation bearing can be predigested to the model which are made up of the nonlinear spring and damper in two horizontal direction and the linear spring in the vertical direction, the Combin 14 element is employed to simulate vertical stiffness; the Combin 40 element is employed to simulate horizontal stiffness in two horizontal directions, the influence of bilinear hardening model and damper in the Combin 40 element can be considered effectively.

\section{THE DESIGN OF LRB}

The dimension and corresponding calculation parameters of LRB are shown in Table $\mathbf{1}$ according to the theory and methods mentioned above.

\section{SELECTION OF SEISMIC GROUND MOTIONS AND TRAIN LOAD}

Code for seismic design of railway engineering [14] provides that: the horizontal earthquake action along the longitudinal and the transverse direction should be calculated respectively for the aseismic checking computation of bridge, the most disadvantaged force combinations are Ex+0.65Ex 
Table 1. Dimension and Calculation Parameters of LRB

\begin{tabular}{|c|c|c|c|l|l|l|l|}
\hline $\begin{array}{l}\text { Number of } \\
\text { LRB }\end{array}$ & $\begin{array}{l}\text { Number of } \\
\text { Lead Plug }\end{array}$ & $\begin{array}{l}\text { Diameter of } \\
\text { LRB(mm) }\end{array}$ & $\begin{array}{l}\text { Height of } \\
\text { LRB(mm) }\end{array}$ & $\begin{array}{l}\text { Diameter of Lead } \\
\text { Plug(mm) }\end{array}$ & $\begin{array}{l}\text { Pre-yield stiff- } \\
\text { ness(kN/mm) }\end{array}$ & $\begin{array}{l}\text { Post-yield Stiffness } \\
\text { (kN/mm) }\end{array}$ & $\begin{array}{l}\text { Yield } \\
\text { Load(kN) }\end{array}$ \\
\hline \hline 2 & 4 & 1100 & 200 & 100 & 36.90 & 5.67 \\
\hline
\end{tabular}

and Ey+0.65Ey. In this paper, El Centro wave, Taft wave and Parkfield wave are used to calculate the seismic responses of bridge, length of be confined to, the paper list only the computation results of seismic ground motions of El Centro earthquake wave. ICE high-speed train of Germany is employed as the vehicle live load, the train marshalling is: $2 \times$ (train+train+trailer+train+train+trailer+train+train). The acceleration time history curve of earthquake wave are given in Figs. (3-5).

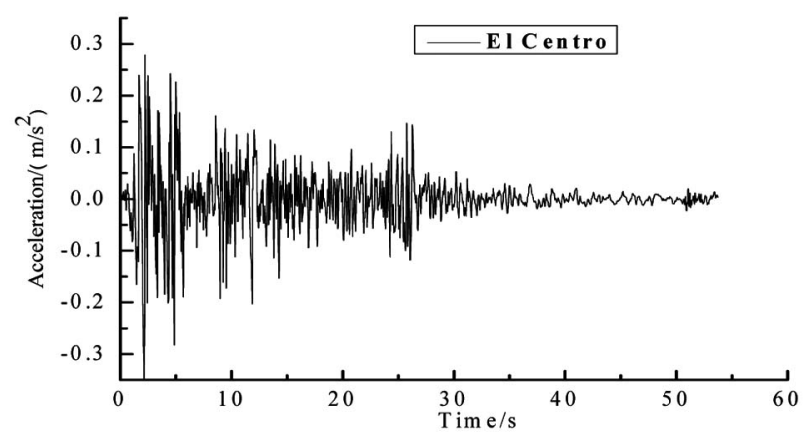

Fig. (3). Acceleration time history curve of El Centro earthquake wave.

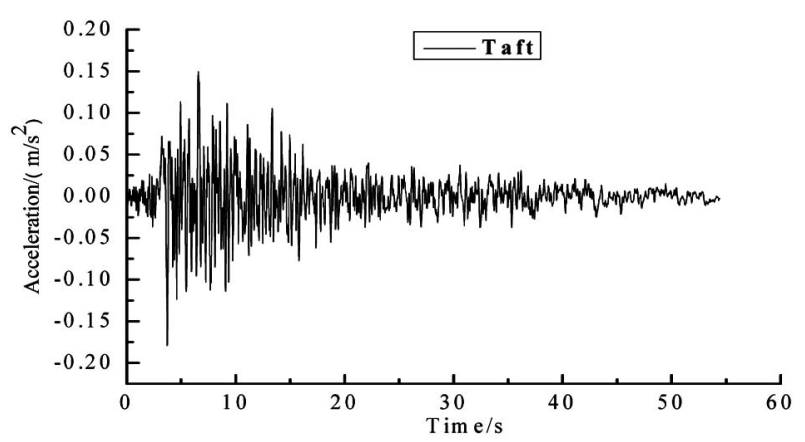

Fig. (4). Acceleration time history curve of Taft earthquake wave.

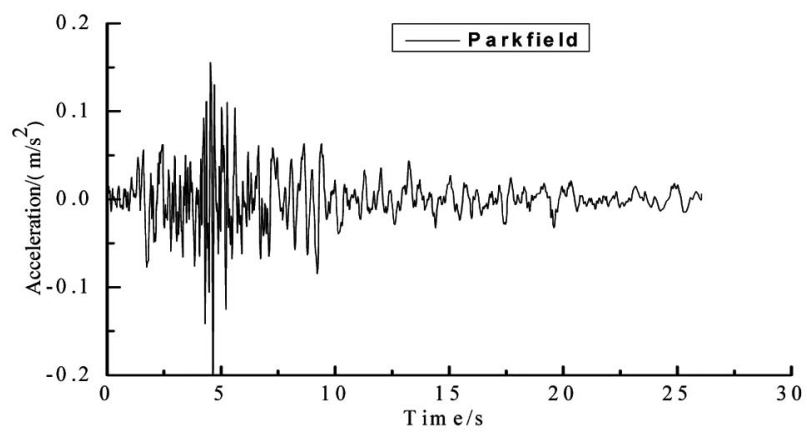

Fig. (5). Acceleration time history curve of Parkfield earthquake wave.

\section{CALCULATING AND ANALYZING OF DYNAMIC RESPONSES OF HIGH-SPEED RAILWAY BRIDGE FABRICATED LRB}

\section{Working Conditions}

In this paper, three sorts of working conditions and their combinations are considered for analyzing the seismic responses and the seismic isolation effect of the seismic isolated bridge.

(1) The bridge fabricated common bearings or LRB are considered respectively, the dimension and corresponding calculation parameters of LRB are shown in Table 1;

(2) The trains pass over bridge at the speed of $160 \mathrm{~km} / \mathrm{h}, 200$ $\mathrm{km} / \mathrm{h}, 250 \mathrm{~km} / \mathrm{h}, 300 \mathrm{~km} / \mathrm{h}, 350 \mathrm{~km} / \mathrm{h}$;

(3) Three sorts of typical strong motion recordings in Ilsite are input, lateral and longitudinal design earthquake and severe earthquake are considered respectively, adapting force combinations of $\mathrm{Ex}+0.65 \mathrm{Ex}$ and $\mathrm{Ey}+0.65 \mathrm{Ey}$;

Fundamental period of bridge before seismic isolation is $0.592 \mathrm{~s}$, after seismic isolation is $0.888 \mathrm{~s}$. The dynamic timehistory responses are calculated by inputing different strong motion recordings and earthquake strength. The seismic responses time-history curve of pre-and post-seismic isolated bridge under transverse design earthquake with $160 \mathrm{~km} / \mathrm{h}$ train speed and $14 \mathrm{~m}$ pier height are seen in Figs. (6-8); the seismic responses time-history curve of pre-and post-seismic isolated of bridge under transverse severe earthquake with $350 \mathrm{~km} / \mathrm{h}$ train speed and $14 \mathrm{~m}$ pier height are seen in Figs. (9-11); the seismic responses of pre- and post- seismic isolated bridge and the seismic isolation ratio with 350 $\mathrm{km} / \mathrm{h}$ train speed and $14 \mathrm{~m}$ pier height under lateral severe earthquake are seen in Table 2.

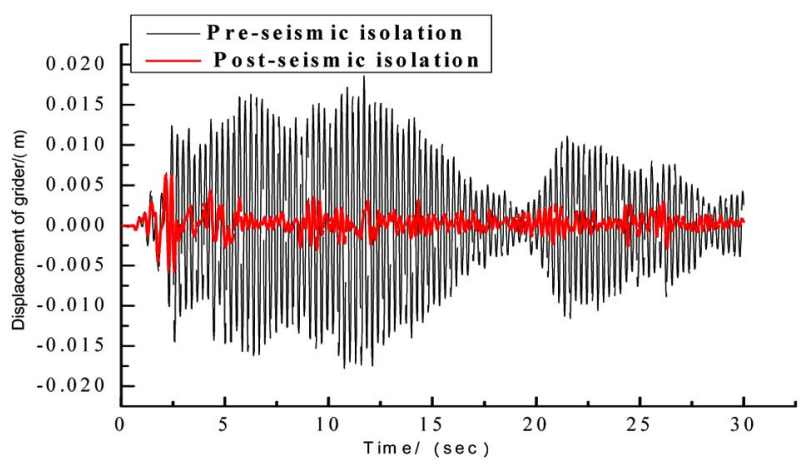

Fig. (6). Time-history curve of pre-and post-seismic isolation displacement of grider under transverse design earthquake with 160 $\mathrm{km} / \mathrm{h}$ train speed an $14 \mathrm{~m}$ pier height. 


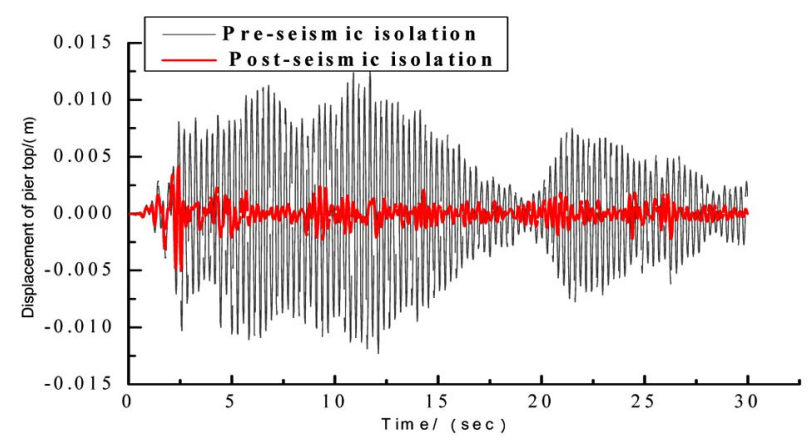

Fig. (7). Time-history curve of pre-and post-seismic isolation displacement of pier top under transverse design earthquake with $160 \mathrm{~km} / \mathrm{h}$ train speed and $14 \mathrm{~m}$ pier height.

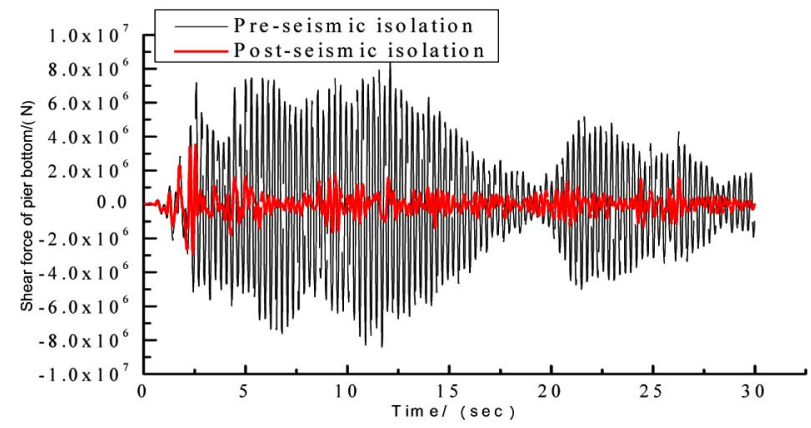

Fig. (8). Time-history curve of pre-and post-seismic isolation shear force of pier bottom under transverse design earthquake with 160 $\mathrm{km} / \mathrm{h}$ train speed and $14 \mathrm{~m}$ pier height.

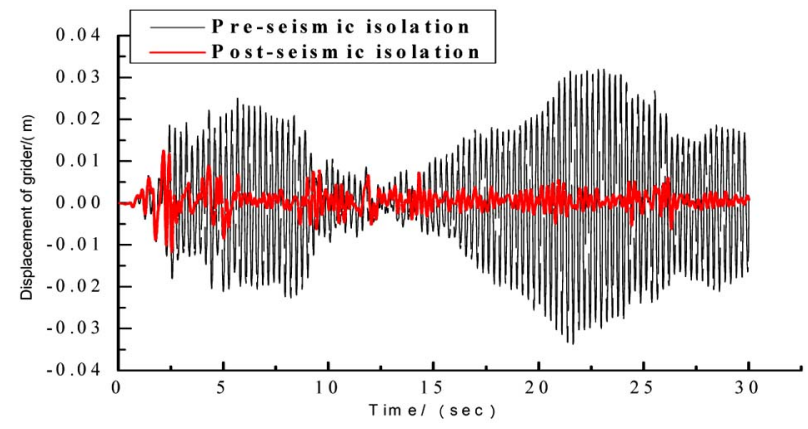

Fig. (9). Time-history curve of pre-and post-seismic isolation displacement of grider under transverse severe earthquake with 350 $\mathrm{km} / \mathrm{h}$ train speed an $14 \mathrm{~m}$ pier height.

Calculation results show that: (1) the seismic responses of the bridge will increase nonlinearly with the rise of the train speed; (2) the seismic isolation effect is comparatively satisfactory when design period is about 1.5 times of the natural vibration period, if design period is larger, the design displacement will increase, the seismic isolation effect becomes bad; (3) the seismic responses can be reduced effectively and seismic response curves are relatively stable after seismic isolation, the seismic isolation ratios are in the range of about from $50.0 \%$ to $70.0 \%$.

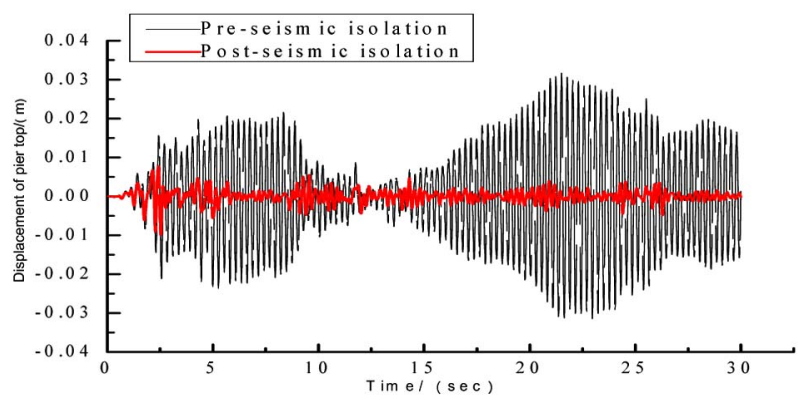

Fig. (10). Time-history curve of pre-and post-seismic isolation displacement of pier top under transverse severe earthquake with $350 \mathrm{~km} / \mathrm{h}$ train speed and $14 \mathrm{~m}$ pier height.

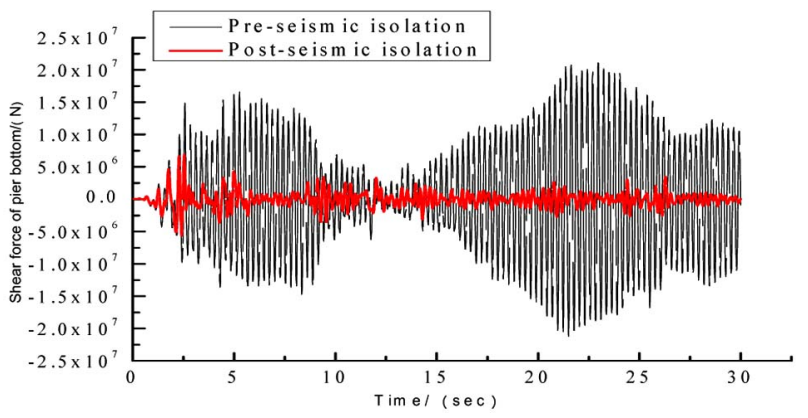

Fig. (11). Time-history curve of pre-and post-seismic isolation shear force of pier bottom under transverse severe earthquake with $350 \mathrm{~km} / \mathrm{h}$ train speed and $14 \mathrm{~m}$ pier height.

Table 2. Responses of Pre- and Post- Seismic Isolation and Seismic Isolation Ratio with $350 \mathrm{~km} / \mathrm{h}$ Train Speed and 14m Pier Height Under Lateral Severe Earthquake

\begin{tabular}{|l|c|c|c|}
\hline $\begin{array}{l}\text { Responses of } \\
\text { Bridge }\end{array}$ & $\begin{array}{l}\text { Transversal } \\
\text { Displacement of } \\
\text { the Grider(m) }\end{array}$ & $\begin{array}{l}\text { Transversal } \\
\text { Displacement of } \\
\text { Pier-top(m) }\end{array}$ & $\begin{array}{l}\text { Shearing } \\
\text { Force of Pier- } \\
\text { Bottom(N) }\end{array}$ \\
\hline \hline $\begin{array}{l}\text { Responses of } \\
\text { pre- seismic isolation }\end{array}$ & 0.0269 & 0.0250 & $1.680 \mathrm{e} 7$ \\
\hline $\begin{array}{l}\text { Responses of post- seismic } \\
\text { isolation }\end{array}$ & 0.0125 & 0.00828 & $7.035 \mathrm{e} 6$ \\
\hline Seismic isolation ratio (\%) & 53.5 & 66.9 & 58.1 \\
\hline
\end{tabular}

*Seismic isolation ratio $\lambda_{e}=\frac{e_{0}-e}{e_{0}}, \lambda_{e}$ is seismic isolation ratio, $e_{0}$ is maximum response of structure without dampers; $e$ is maximum response of structure with dampers。

\section{CONCLUSIONS}

In this paper, the equivalent bilinear model of hysteretic characteristics of LRB is established, the calculation method and reasonable varying range of dynamic parameter of the seismic isolation device are presented, and the calculation result shows that:

(1) The seismic responses of the bridge will increase with the rise of earthquake intensity; 
(2) Because of the strong excitation action of the earthquake, the influence of the vehicle live loading is slight, the seismic responses of the bridge will increase nonlinearly with the rise of the train speed;

(3) Compared to the common bearing, the LRB can reduce not only the displacement of pier top under earthquake, but also the bending moment and the shear force of the bridge are reduced greatly at the same time; the seismic responses reduce effectively and the seismic response time-history curves are relatively stable after seismic isolation, the seismic isolation effect is satisfactory;

(4) The selection of dynamic parameters of LRB is the key to reduce the seismic responses of structure, moreover; the parameter optimization of seismic isolation device of bridge should be emphasized in further research.

\section{ACKNOWLEDGEMENTS}

This study is supported by Grant 2008G031-17 and 2009G-024 from Minster of Railways of China. This support is gratefully acknowledged.

\section{REFERENCES}

[1] W. H. Robinson, "Lead rubber hysteretic bearing suitable for protecting structures during earthquakes", Earthquake Eng. Struct. Dyn., vol. 10, no.4, pp. 593-604, 1982.

[2] J. M. Kelly, "Aseismic base isolation: review and bibliography", Soil Dyn. Earthquake Eng., vol. 5, no.4, pp. 202-216, 1986.
[3] I. G.. Buckle, and R. L. Mayes, "Seismic isolation: history, application, and performance-a world view", Earthquake Spectra, vol. 6 , no.2, pp. 161-201, 1990.

[4] J. S. Hwang, L. H. Sheng, and J. H Gates, "Practical analysis of base-isolated bridges with bilinear hysteresis characteristics", Earthquake Spectra, vol. 10, no.4, pp. 705-727, 1994.

[5] J. S. Hwang, and L. H. Sheng, "Equivalent elastic seismic analysis of base-isolated bridges with lead-rubber bearings", Eng. Struct., vol.16, no.3, pp. 201-209, 1994.

[6] I. Buckle, S. Nagarajaiah, and K. Ferrell, "Stability of elastomeric isolation bearings: experimental study", J. Struct. Eng., vol.128, no.1, pp. 3-11, 2002.

[7] M. C. Kunde, and R. S. Jangid, "Effects of pier and deck flexibility on the seismic response of isolated bridges", J. Bridge Eng., vol. 11, no.1, pp. 109-121, 2006.

[8] Y. K. Wen, "Method for random vibration of hysteretic systems", Eng. J. Mech. Div, ASCE, vol.102, no.2, pp. 249-263, 1976.

[9] Y. J. Park, Y. K. Wen, and A. H. S. Ang, "Random vibration of hysteretic systems under bidirectional ground motions", Earthquake Eng. Struct. Dyn., vol. 14, no.4, pp. 543-557, 1986.

[10] S. Nagarajaiah, A. M. Reinhorn, and M. C. Constantinou, "Nonlinear dynamic analysis of 3D-base isolated structures", J. Struct. Div, ASCE, vol. 117, no.7, pp. 2035-2054,1991.

[11] AASHTO, Guide specifications for seismic isolation design (2nd). Washington, D.C: American Association of State Highway and Transportation Officials, 2000.

[12] K. Kawashima, Manual for nenshin design of highway bridges. The Second U.S.-Japan Workshop on Earthquake Protective Systems for Bridges, Tsukuba City: Public Works Research Institute, Japan, 1992, pp. 195-220.

[13] Ministry of Works and Development. Design of lead-rubber bearings. Wellington: Civil Division Publication CDP 818/A, 1983, pp. 18-24.

[14] Ministry of Railways of the People's Republic of China, Code for seismic design of railway engineering, Beijng: China Planning Press, China, 2006. (In Chinese) 